\title{
Higher mortality of patients on haemodialysis with pancreatic diabetes compared to type 2- diabetes
}

\author{
Gert Bodlaj and Georg Biesenbach*
}

\begin{abstract}
In rare cases (1-8\%) diabetic patients with end-stage renal disease (ESRD) suffer from diabetic nephropathy (dNP) due to pancreatic diabetes mellitus (PDM). Aim of this study was to investigate differences in the outcome of patients with PDM and those with type 2 diabetes.

In a retrospective study we evaluated 96 diabetic patients, who started hemodialysis (HD) in our dialysis centre (1997-2005). In 12 patients PMD was diagnosed, and 84 patients had type 2 diabetes. In both groups we compared vascular risk factors and prevalence of vascular diseases at the start of dialysis. We also evaluated incidence of malnutrition, and 5-year survival in both patient groups.

The vascular risk factors were similar in both patient groups, also the prevalence of vascular diseases at the initiation of HD was similar in both groups. In the patients with PDM the mean BMI $\left(\mathrm{kg} / \mathrm{m}^{2}\right)$ was lower $(22+3$ versus $25+3)$, and also their serum albumin was lower $(2.7+0.3$ versus $3.4+0.3 \mathrm{~g} / \mathrm{dl}, \mathrm{p}<0.05)$. Four of these patients $(33 \%)$ developed malnutrition (BMI < 18.5). In the patients with PDM the age adjusted 5-year survival was significantly lower ( $8 \%$ versus $27 \%, p<0.05)$ than in the type 2 diabetic patients.

Conclusions in HD-treated patients with type 2 diabetes or PDM the prevalence of vascular diseases was not significantly different. The lower survival of PDM patients can be related to poor nutrition status.
\end{abstract}

Keywords: Pancreatic diabetes, End-stage renal disease, Outcome

\section{Introduction}

In rare cases (1-8\%) patients w/ith pancreatic diabetes (PDM) develop diabetic nephropathy (dNP) with ESRD [1-4] The aim of this retrospective study was to investigate differences in the clinical outcome of uremic patients with dNP due to type 2 diabetes or PDM. There are only few data in the literature dealing with PDM and ESRD [3]. In a recent study was reported, that only $1-5 \%$ of diabetic patients with ESRD suffer from pancreatic diabetes [Choudhuri et al. 2009]. Aim of our study was to investigate prevalence of atherosclerosis and to evaluate differences in the outcome of patients with PDM and those with type 2 diabetes.

\footnotetext{
* Correspondence: georg.biesenbach@liwest.at

From the 2nd Department of Medicine, Section Nephrology, General
} Hospital Linz, Austria

(C) 2012 Bodlaj and Biesenbach; licensee BioMed Central Ltd. This is an Open Access article distributed under the terms of the Creative Commons Attribution License (http://creativecommons.org/licenses/by/2.0), which permits unrestricted use, distribution, and reproduction in any medium, provided the original work is properly cited.

\section{Patients}

During the years 1997-2005 we selected 144 type 2 diabetic patients who started chronic hemodialysis (HD) in our dialysis centre. We excluded patients with death within the first three months of HD $(n=24)$, kidney transplantation $(\mathrm{n}=8)$ and patients $(\mathrm{n}=16)$ with vascular nephropathy (vNP). Finally, a total of 96 patients with dNP were included in a retrospective study, 12 patients of them with dNP due to PDM versus 84 patients with dNP caused by type 2 diabetes. The diagnosis of PDM was based on hyperglycemia after recurrent onset of acute pancreatitis and/or pancreas resection. The diagnosis of dNP was based on proteinuria, normal urine sediment, normal kidney size and long acting diabetes. The diagnosis of vNP was defined as renal atherosclerosis and/or shrinkage of a kidney.

In both groups we compared major vascular risk factors and prevalence of vascular diseases at the start of dialysis. We also evaluated incidence of malnutrition,

\section{Biomed Central}


and 5-year survival in both patient groups as well as the prevalence of vascular diseases at the start of HD. Diagnosis of cerebrovascular disease (CVD), coronary artery disease (CAD) and of peripheral vascular disease (PVD) was described in the literature [5]. We also investigated the nutritional status, the frequency of malnutrition and of exocrine pancreatic insufficiency, associated with chronic diarrhoea [6]. The observation period of the study was five years. Thus, in our analysis, the endpoint of the study was death by any cause, while the basal disease PDM or type 2 diabetes were considered as covariables.

For statistical analysis the SPSS for Windows statistical program was used. The statistical methods included the chi-squared test for comparing differences between the groups, and the unpaired student's test for testing unequal variances as well as the Kuscal test for comparisons among the groups. A p-value of less than 0.05 was considered significant.

\section{Results}

At the time of initiating HD treatment the patients with PDM were significantly younger than those with type 2 diabetes (mean age 56 versus 63 years). The vascular risk factors were similar in both groups, only cholesterol was lower in the PDM patients; the HbA1c values were not different (mean control levels 7.5 versus $7.6 \%$ ), however, the patients with PDM required significantly less insulin. All baseline data of both patient groups are presented in Table 1 . In our patients it can be assumed, that dNP was the cause of ESRD. The clinical diagnosis of dNP was confirmed by histological investigations in 44 diabetic patients.

The prevalence of macrovascular diseases at the start of dialysis was not significantly different. The prevalence of CAD was $66 \%$ in the type 2 diabetic patients versus $50 \%$ in the group. with PDM. The prevalence of CVD was 33 versus $45 \%$ and PVD 50 versus $45 \%$.

The nutritional status at the start of HD was poor in the PDM patients. The frequency of underweight (BMI $<21$ ) was $50 \%$ versus $9 \%(\mathrm{p}<0.05)$. Four patients with PDM (33\%) developed malnutrition (BMI < 18.5). In six patients an exocrine pancreatic insufficiency could be observed (50\%). The prognostic parameter s-albumin was significantly lower in the PDM group $(2.7+0.3$ versus $3.4+0.3 \mathrm{~g} / \mathrm{l}, \mathrm{p}<0.05)$. The 5 - year survival was significantly lower in the group with PDM 8\% versus 27\% $(\mathrm{p}<0.05)$ The observation period of the study was five years. We measured the 5-year - absolute survival rates, which describe the percentage of patients that are alive five years after their disease is diagnosed. The most common causes of death were cardiovascular events, in the PDM group $60 \%$ versus $65 \%$ in the type 2 diabetic patients. Infection was cause of death in $27 \%$ of the
Table 1 Baseline data at the start of dialysis

\begin{tabular}{|c|c|c|}
\hline & $\begin{array}{l}\text { Pancreatic } \\
\text { diabetes } \\
(\mathrm{n}=12)\end{array}$ & $\begin{array}{l}\text { Type } 2 \\
\text { diabetes } \\
(\mathrm{n}=84)\end{array}$ \\
\hline Age (years) & $56 \pm 6^{*}$ & $63 \pm 8^{*}$ \\
\hline Sex (female \%) & $50 \%$ & $52 \%$ \\
\hline Diabetes duration (years) & $17 \pm 7$ & $18 \pm 6$ \\
\hline $\mathrm{HbA} 1 \mathrm{c}(\%)$ & $7.5 \pm 1.3$ & $7.6 \pm 1.1$ \\
\hline Body weight (kg) & $59 \pm 7^{* *}$ & $70 \pm 11^{* *}$ \\
\hline BMI $\left(\mathrm{kg} / \mathrm{m}^{2}\right)$ & $22 \pm 3^{*}$ & $25 \pm 4^{*}$ \\
\hline C-peptide basal (ng/ml) & $0.9 \pm 0.3^{*}$ & $1.9 \pm 0.6^{*}$ \\
\hline Systolic blood pressure (mm Hg) & $136 \pm 12$ & $137 \pm 10$ \\
\hline $\begin{array}{l}\text { Diastolic blood pressure (mm } \\
\mathrm{Hg})\end{array}$ & $86 \pm 9$ & $87 \pm 8$ \\
\hline \multicolumn{3}{|l|}{ Antidiabetic therapy (\%) } \\
\hline Diet and sulfonylurea & 0 & $5 \%$ \\
\hline Conventional insulin therapy & $50 \%$ & $44 \%$ \\
\hline Intensified insulin therapy & $50 \%$ & $41 \%$ \\
\hline Insulin dose (IU/day) & $22+11^{*}$ & $32+11^{*}$ \\
\hline \multicolumn{3}{|l|}{ Vascular access (n/\%) } \\
\hline Arteriovenous fistula & $10(83 \%)$ & $64(76 \%)$ \\
\hline Permcath-dialysis catheter & $2(17 / \%)$ & $20(24 \%)$ \\
\hline Insulin dose (IU/day) & $22 \pm 11^{*}$ & $32 \pm 16^{*}$ \\
\hline $\begin{array}{l}\text { Duration of dialysis (hours// } \\
\text { week) }\end{array}$ & $13(12-15)$ & $13(12-15)$ \\
\hline $\begin{array}{l}\text { Kt } / \text { (three month after start of } \\
\text { HD) }\end{array}$ & 1.3 & 1.4 \\
\hline
\end{tabular}

PDM patients and $21 \%$ of the patients with type 2 diabetes (NS).

\section{Discussion}

Diabetes caused by exocrine pancreatic disease appears to be underestimated and may comprise $8 \%$ or more of the general diabetic patient population [4] In our study the causes of PDM were chronic fibrocalculous pancreatitis $(n=8)$ and pancreas resection due to pancreas neoplasma $(n=4)$ The vascular risk factors were similar in both patient groups. The traditional risk factors and the non-traditional risk factors [7] are shown in Table 2. Parathormon (PTH) was no routine measurement in earlier years. PTH values were available in $68 \%$ of all patients. ESRD patients with PDM versus type 2 diabetes show a similar vascular risk profile and a comparable high prevalence of vascular diseases, though patients with PDM were younger. The CRP values, considered as vascular risk factors, were slightly higher in the patients with PDM, but difference was not significant. Similar data are described in the literature [8]. All prognostic parameters are also summarized in Table 2. It can be assumed that the low patient survival is associated with the poor nutrition status of the PDM patients. This study has several limitations particularly 
Table 2 Traditional and non-traditional risk factors and prescribed medication

\begin{tabular}{|c|c|c|}
\hline & $\begin{array}{l}\text { Pancreatic } \\
\text { diabetes }\end{array}$ & $\begin{array}{l}\text { Type } 2 \\
\text { diabetes }\end{array}$ \\
\hline \multicolumn{3}{|l|}{ Traditional vascular risk factors } \\
\hline Fasting blood glucose (mg/dl) & $146 \pm 22$ & $14 \pm 22$ \\
\hline Systolic blood pressure (mm Hg) & $134 \pm 12$ & $136 \pm 12$ \\
\hline Diastolic blood pressure (mm Hg) & $82 \pm 7$ & $84 \pm 8$ \\
\hline Uncontrolled hypertension & $83 \%$ & $90 \%$ \\
\hline Cholesterol (mg/dl) & $142 \pm 42^{* *}$ & $196 \pm 36^{* *}$ \\
\hline Smoking & 33 & 30 \\
\hline \multicolumn{3}{|l|}{ Non-traditional risk factors } \\
\hline $\mathrm{BMI}<21\left(\mathrm{~kg} / \mathrm{m}^{2}\right)$ & $50 \%$ & $9 \%$ \\
\hline BMI < 18.5 (malnutrition) & $33 \%$ & 0 \\
\hline CRP $(\mathrm{ng} / \mathrm{ml})$ & $1.4 \pm 0.9$ & $0.8 \pm 0.6$ \\
\hline Serum albumin (g/dl) & $2.7 \pm 0.3^{*}$ & $3.4+0.3^{*}$ \\
\hline Hemoglobin (gm/dl) & $10(8-12)$ & $11(8-13)$ \\
\hline Triglycerides $(\mathrm{mg} / \mathrm{dl})$ & $123 \pm 44$ & $156 \pm 42$ \\
\hline $\begin{array}{l}\text { Fluid overload (ultrafiltration } \\
\text { necessary) }\end{array}$ & $33 \%$ & $24 \%$ \\
\hline \multicolumn{3}{|l|}{ Prescribed medication } \\
\hline Iron substitution & $27 \%$ & $17 \%$ \\
\hline 25-hydroxy vitamin D & $66 \%$ & $43 \%$ \\
\hline Statin & $33 \%$ & $44 \%$ \\
\hline Aspirin & $33 \%$ & $29 \%$ \\
\hline ACE inhibitors & $50 \%$ & $52 \%$ \\
\hline
\end{tabular}

${ }^{*} \mathrm{p}<0.05,{ }^{* *} \mathrm{p}<0.01$ Data are expressed as $\mathrm{x}+\mathrm{SD}, \mathrm{x}$ (range) or \%

ther small number of PDM patients, the absence of data on PTH-levels and residual renal function, and the absence of more accurate methods of nutritional assesment However, our results suggest that malnutrition is possible explanation to the outcome differences.

\section{Conclusion}

The prevalence of atherosclerosis is not significantly different in both, patients on hemodialysis with PDM versus type 2 diabetes. In patients with PDM the 5-year surviv 1 is lower than in the type 2 diabetic patients. We confirm, that there are limitations of our study, due to the retrospective analysis of the data and due to the small patient group with PDM.

\section{Authors' contributions}

GB drafted the manuscript. GB revised the manusript. Both authors read and approved the final manuscript.

\section{Competing interests}

The authors declare that they have no competing interests.

Received: 28 October 2011 Accepted: 23 March 2012

Published: 23 March 2012
References

1. Ito T, Olsuki M, Itoi T, Shimosegawa T, Funakosi A, Shiratory $K$, et al: Pancreatic Diabetes in follow-up survey of chronic pancreatitis in Japan. J Gastroenterol 2007, 42:291-297.

2. Sjoberg RJ, Kid GS: Pancreatic diabetes mellitus. Diabetes Care 1989, 12:715-724.

3. Choudhuri G, Lakshmi CP, Goel A: Pancreatic diabetes. Trop Gastroenterol 2009, 30:71-75

4. Hardt PD, Brendel MD, Kloer HU, Bretzel RG: Is pancreatic diabetes (type $3 c$ diabetes) underdiagnosed and misdiagnosed? Diabetes Care 2008, 31(Suppl 2):S165-S169.

5. Biesenbach G, Königsrainer A, Gross C, Margreiter R: Progression of macrovascular diseases is reduced in type 1 diabetic patients after more than 5 years successful combined pancreas-kidney transplantation in comparison to kidney transplantation alone. Transpl Int 2005, 18:1054-1060.

6. Chattopadhyay PS, Mukhopadhyay A, Chattopadhyay R, Gupta S: Macrovascular disease is not that uncommon in fibrocalculos pancreatic diabetes. Diabetes Care 1995, 17:462-463.

7. Bergström J: Nutrition and mortality in hemodialysis. J Am Soc Nephrol 1995, 6:1329-1341

8. Weiner DE, Tighiouart H, Elsayed F, Griffith JL, Salem DN, Levey AS, Sarnak MJ: The relationship between nontraditional risk factors outcomes in individuals with stage 3 to $4 \mathrm{ckd}$. Am J Kidney Dis 2008, 51:212-223.

doi:10.1186/1758-5996-4-9

Cite this article as: Bodlaj and Biesenbach: Higher mortality of patients on haemodialysis with pancreatic diabetes compared to type 2diabetes. Diabetology \& Metabolic Syndrome 2012 4:9.

\section{Submit your next manuscript to BioMed Central and take full advantage of:}

- Convenient online submission

- Thorough peer review

- No space constraints or color figure charges

- Immediate publication on acceptance

- Inclusion in PubMed, CAS, Scopus and Google Scholar

- Research which is freely available for redistribution

Submit your manuscript at www.biomedcentral.com/submit 